\title{
Positive correlation of serum parathormone and prostate specific antigen levels in prostate cancer
}

\author{
Aydin $\mathrm{O}^{1}$, Eren $\mathrm{E}^{2}$, Yalcinkaya $\mathrm{S}^{3}$, Yilmaz $\mathrm{N}^{1}$, Eroglu $\mathrm{M}^{3}$, Ellidag $\mathrm{HY}^{1}$ \\ Central Laboratories of Antalya Training and Research Hospital of Ministry of Health, Antalya, Turkey. \\ necatyilmaz@hotmail.com
}

\begin{abstract}
Objectives: Clinical and experimental observations reveal the exact role of vitamin $\mathrm{D}$ in prostate cancer. Yet, a complete understanding of the issue necessitates the evaluation of the exquisite mechanisms that involve full actors of the calcium homeostasis in relation.

Background: Besides the role of vitamin D, parathyroid hormone (PTH) is now understood to be a mitogen for prostate cancer cells, and calcium has already been known for such role. The interplay between renin-angiotensin-aldosterone system effector hormones and calcium homeostasis attracts attention in recent studies. Methods: Twenty five patients with prostate cancer (median age 66 (62-67) years) who had presented at the Urology Outpatient Clinic were prospectively included in the study. Also, 30 volunteer controls (median age 63 (60-70) years) were enrolled for comparison. Serum total PSA, intact PTH, calcium, aldosterone and 25-hydroxy vitamin $\mathrm{D}$ levels were detected in a selected group of patients with prostate cancer.

Results: The vitamin D levels were lower in PCa patients in line with some of the previous studies, supporting the role of vitamin $\mathrm{D}$ in prostate cancer. We also observed a positive correlation between PTH and PSA both in PCa patients and the controls.

Conclusion: Our findings indicate that like age and race, PSA is associated with PTH. The role of PTH, as a master of calcium homeostasis, seems to be neglected in prostate carcinogenesis, concerning a very few number of studies pertaining to the subject in the literature (Tab. 2, Fig. 2, Ref. 19). Text in PDF www.elis.sk. Key words: prostate carcinoma, vitamin D, parathyroid hormone, prostate specific antigen, aldosterone.
\end{abstract}

The major features of the descriptive epidemiology of prostate cancer (PCA), i.e. increasing incidence with age, black race and residence at northern latitudes, resembled the descriptive epidemiology of vitamin D deficiency (1). Several ecological studies have shown a relationship between lower sunshine exposure and higher prostate cancer prevalence or mortality. Subsequent clinical observations support the hypothesis that vitamin D may become an agent to prevent the development of prostate cancer $(2,3)$.

Human prostate cells express the receptor for vitamin D (4). It is shown that many genes in prostate cancer cells are positively or negatively regulated through the vitamin $\mathrm{D}$ receptor (5). In general 1,25-dihydroxyvitamin $\mathrm{D},(1,25(\mathrm{OH}) 2 \mathrm{D})$ suppresses proliferation and stimulates differentiation of cancer cells.

The circulating $1,25(\mathrm{OH}) 2 \mathrm{D}$ is formed in the kidney under stimulation of PTH and negative feedback by serum calcium and itself.

Conversely, increased exposure to UV light, increased dietary intakes of calcium and of vitamin D down-regulate production of PTH.

Concerning the close relationship with vitamin D, PTH is a suspicious cancer promoter. PTH promotes the proliferation and

${ }^{1}$ Central Laboratories of Antalya Training and Research Hospital of Ministry of Health, Antalya, Turkey, ${ }^{2}$ Antalya Public Health Center of Ministry of Health, Antalya, Turkey, and ${ }^{3}$ Urology Clinic of Antalya Training and Research Hospital of Ministry of Health, Antalya, Turkey

Address for correspondence: N. Yilmaz, Antalya Education and Research Hospital Central Laboratory Kazim Karabekir Cad., 07400 Antalya, Turkey. Phone: +905053578305 migration of prostate cancer cells and negatively predicts survival. Also, high intake of dietary calcium has already been reported to be an increased risk of prostate cancer (6).

In extrarenal cells and tissues 25-hydroxyvitamin D (25(OH)D) can be hydroxylated to $1,25(\mathrm{OH}) 2 \mathrm{D}$ under the influence of cytokines. This extrarenal 1,25(OH)2D stimulates cell differentiation in a paracrine way and might play a role in cancer prevention(7).

In addition to its role in calcium and phosphate homeostasis, $1,25(\mathrm{OH}) 2 \mathrm{D}$ influences a wide variety of other biological processes, including the immune response, insulin secretion, cardiovascular function, and blood pressure.

$1,25(\mathrm{OH}) 2 \mathrm{D}$ has been identified recently as a regulator of the renin-angiotensin-aldosterone system. Aldosterone and $1,25(\mathrm{OH}) 2 \mathrm{D}$ co-operates in the regulation of cell function and this interaction seems to be the result of cross talk between nongenomic and genomic steroid hormone signaling pathways (8).

Thus, it is critical to understand what factors may regulate the conversion of $25(\mathrm{OH}) \mathrm{D}$ to $1,25(\mathrm{OH}) 2 \mathrm{D}$ within prostate cells. In this report we examined major actors that are likely to take part as regulators of vitamin D, in very delicately selected groups of patients and controls.

\section{Material and methods}

Study population and clinical examinations

Twenty five patients with prostate cancer (median age 66 (62-71) years) who had presented at the Urology Outpatient Clinic 
were prospectively included in the study. Also, 30 volunteer controls (median age 63 (60-70)years) were enrolled for comparison.

The patients were evaluated by the same urologist. All subjects had full physical examination and were asked to complete a general questionnaire and gave informed consent before the onset of study. The questions included: the age, social-economic status, origin of ancestors, status of physical activity, smoking, alcohol consumption, and detailed medical history. Consequently, blood pressure was measured manually with a sphygmomanometer. Body mass index was calculated as weight in kilograms divided by height in square meters. Hypertension was defined as systolic blood pressure of at least $140 \mathrm{~mm} \mathrm{Hg}$, diastolic blood pressure of at least $90 \mathrm{~mm} \mathrm{Hg}$, otherwise physician diagnosed hypertension.

Those with a known past history of any major diseases like cardiac disease, renal, hepatic or endocrine disease were excluded. None of the participants in the present study were using drug medications including anti-hypertensive reagents, diuretics, lipid lowering agents, vitamins or mineral drugs. Subjects with hypertension or osteoporosis, smokers and alcohol users were also excluded.

The subjects were locals with average family income, strongly favoring a common dietary habits, and routine daily life.

Final diagnosis of each patient was confirmed by histopathologic evaluation of prostate needle biopsies. After the pathology reports were inspected, only the patients with a Gleason scores of 5,6 and 7 were included into the study. Any patients with a clinical or radiologic suspicion of metastatic prostate cancer were excluded.

This study was performed in accordance with the ethical standards set by the Declaration of Helsinki and was approved by the local ethics committee.

\section{Analytical methods}

Blood Sample Collection:

Blood samples were obtained after an overnight fasting state. Serum samples were then separated from the cells by centrifugation at $3000 \mathrm{rpm}$ for 10 minutes. Serum total PSA (PSA), intact PTH, calcium and cholesterol (TC), triglycerid (TG), high-density lipoprotein (HDL), low-density lipoprotein (LDL) levels were measured freshly. Remaining serum portions were stored at $-80^{\circ} \mathrm{C}$ and used to analyze $25(\mathrm{OH})$ vitamin D and aldosterone.

PTH and PSA levels were measured using the Access Hybridtech two-site immunoenzymatic "sandwich" assay (Beckman Coulter, Fullerton, CA). Serum calcium levels and lipid panel were determined by using commercially available assay kits(Abbott) with an autoanalyzer (Architect $\AA_{\mathrm{c}} 16000$, Abbott Diagnostics).

The LIAISON® $25 \mathrm{OH}$ Vitamin D assay (DiaSorin) was performed on the LIAISON® analyzer according to the manufacturer's instructions. The LIAISON $25 \mathrm{OH}$ Vitamin D assay is a direct competitive chemiluminescence immunoassay.

Aldosterone was measured through the principle of competitive enzyme immunoassay test(DRG ${ }^{\circledR}$ Aldosterone (EIA-4600) performed on Etimax microelisa analyser.

\section{Statistical analysis}

Statistical analyses were carried out using the statistical software version 11.5.1.0 (MedCalc $\AA$, Mariakerke, Belgium). In nor-
Table 1: Age, BMI and lipid parameters showed no significant difference between groups.

\begin{tabular}{lccc}
\hline Parameter (median-IQR) & Patients $(\mathrm{n}=25)$ & Controls $(\mathrm{n}=30)$ & $\mathrm{P}$ \\
\hline Age $($ years $)$ & $66(62-71)$ & $63(60-70)$ & 0,18 \\
BMI $(\mathrm{kg} / \mathrm{m} 2)$ & $26(24-32)$ & $26(24-30)$ & 0,66 \\
TC $(\mathrm{mg} / \mathrm{dl})$ & $210(195-230)$ & $194(177-221)$ & 0,16 \\
TG $(\mathrm{mg} / \mathrm{dl})$ & $135(94-189)$ & $177(113-213)$ & 0,31 \\
LDL $(\mathrm{mg} / \mathrm{dl})$ & $135(107-147)$ & $119(104-146)$ & 0,26 \\
HDL $(\mathrm{mg} / \mathrm{dl})$ & $44(37-55)$ & $42(35-47)$ & 0,23 \\
\hline
\end{tabular}

Table 2: Serum PSA levels were significantly higher in PCa patients as expected. 25-(OH)2D levels were significantly lower in PCa group compared to the controls. Serum PTH, calcium and aldosterone values were indifferent between groups, and were in normal limits. Aldosteron mean difference was very close to the significance value.

\begin{tabular}{lcccc}
\hline parameter & PCa $(25)$ & Controls $(30)$ & Normal & $\mathrm{p}$ \\
\hline PSA $(\mathrm{ng} / \mathrm{mL})$ & $8,4(6,6-13,9)$ & $1,3(0,9-1,7)$ & $0,01-1$ & $<0,0001$ \\
$25-(\mathrm{OH}) 2 \mathrm{D}(\mathrm{ng} / \mathrm{mL})$ & $13,9(10,6-16,3)$ & $17,3(13,6-21,1)$ & $20-60$ & 0,03 \\
$\mathrm{PTH}(\mathrm{pg} / \mathrm{mL})$ & $42,8(37-52,5)$ & $42,6(34,2-54,9)$ & $15-88$ & 0,66 \\
$\mathrm{Cal}(\mathrm{mg} / \mathrm{dL})$ & $10(9,7-10,1)$ & $9,7(9,6-9,8)$ & $8,2-10,9$ & 0,11 \\
Aldo $(\mathrm{pg} / \mathrm{mL})$ & $172(142-242)$ & $221(172-256)$ & $25-315$ & 0,06 \\
\hline
\end{tabular}

mally distributed groups the results were presented with mean and $\mathrm{SD}$, otherwise with medians. The significance of the differences between groups was determined by Student's unpaired t-test for normal distributions, and by the Mann-Whitney U-test in abnormal distributions. Pearson correlation coefficient and Spearman correlation coefficient were used to test the strength of any associations between different variables. $p$ values less than 0.05 were accepted as the significance level.

\section{Results}

Demographic and clinical data of prostate cancer patients and controls are summarized in Table 1. The patients and controls were similar in age, BMI and lipid parameters.

We evaluated associations between PSA, total serum calcium, serum intact PTH, serum $25(\mathrm{OH}) \mathrm{D}$, and serum aldosterone levels in patients with PCa, compared to the control group (Tab. 2). Serum PSA levels were significantly higher in PCa patients as

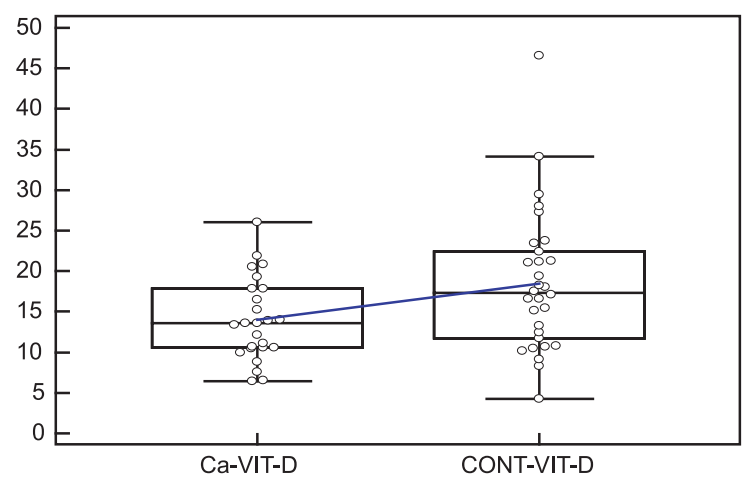

Fig. 1. 25-(OH)D levels were significantly lower in PCa group compared to the controls $(\mathrm{p}=0.03)$. $25-(\mathrm{OH}) \mathrm{D}$ levels in both groups were lower than the threshold reference limit $(20 \mathrm{ng} / \mathrm{ml})$. 

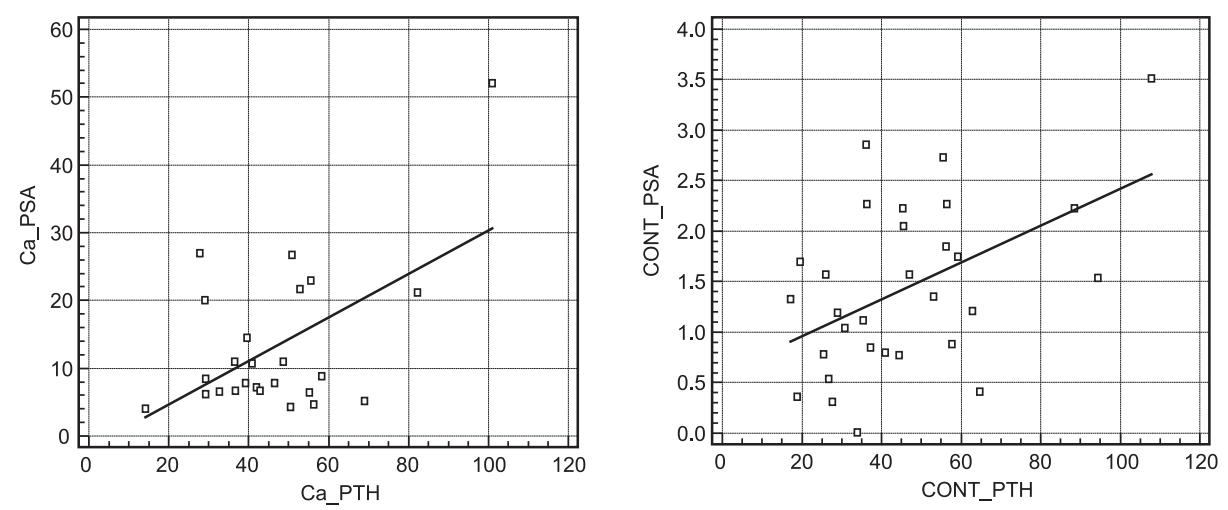

Fig. 2. There was positive correlation between PTH and PSA levels in PCa and control groups.

expected. 25(OH)D levels were significantly lower compared to the controls $(\mathrm{p}=0.03)$. Interestingly, 25(OH)D levels in controls were lower than the threshold reference limit (20 ng/ml) (Fig. 1).

Serum PTH, calcium and aldosterone values were indifferent between groups, and were in normal limits. Aldosterone mean difference was very close to the significance value $(p=0.06)$.

Pearson test showed positive correlations between PTH and PSA levels both in $\mathrm{PCa}$ and control groups $(\mathrm{r}=0.54 \mathrm{p}=0.005 ; \mathrm{r}=0.48$ $\mathrm{p}=0.006$, respectively) (Fig. 2).

\section{Discussion}

Our results were in line with some of the previous ones, supporting the role of vitamin D in PCa $(9,10)$. Of concern is that we observed significant positive correlations between serum PTH and serum PSA in both PCa and control groups with very close statistical coefficients and $p$ values. The correlation may be explained by PTHs role in regulating serum levels of 1,25(OH)2D and thus its potential effect on prostate cells indirectly. But also it should be kept in mind that normal and cancerous prostate cells possess specific receptors for PTH, clearly making a direct and independent effect quite possible. Actually, PTH is a well studied mitogen in the prostate. Administration of PTH increases the proliferation of human prostate cancer cells in tissue culture (11). Previous studies have already shown that even physiologic levels of PTH promote the growth of prostate cancer cells in tissue culture and in vivo (12). PTH injection to rats with prostate cancer xenografts has promoted tumor growth and was accompanied by an increase in serum PSA (13). Epidemiologic studies on serum PTH and prostate disease are very rare. In 2009, an association between serum PTH and serum calcium and serum PSA in men without clinical prostate cancer was presented (14). In contrast to this study, serum calcium levels in our study did not show a correlation with PSA levels. The close statistical numerical values obtained in both controls and PCa patients were of great interest. The finding favors a direct interrelation between PTH and PSA. We believe the relationship is independent of calcium homeostasis mechanism. The lack of correlation between 25(OH) D and PTH was also a hold for our suggestion. In a very recent study,
PSA levels were not correlated with PTH or vitamin D or serum calcium levels in patients with benign prostate hyper (BPH) (15). One of our studies also confirmed this finding (unpublished data). We find the discrepancy valuable, to be an evidence for BPH to own a different pathogenesis from $\mathrm{PCa}$, thus $\mathrm{BPH}$ do not progress to a carcinoma.

It seems quite reasonable that the blood levels of $25(\mathrm{OH}) \mathrm{D}$ influence vitamin D functions in tissues. Yet, it is still unclear to what extent these effects are mediated through direct actions of $25(\mathrm{OH}) \mathrm{D}$ or through indirect effects of the hormone on plasma calcium concentration, PTH levels, or other confounding factors. In human body, vitamin D is tightly regulated by PTH and calcium levels through the actions of renal $1 \alpha-\mathrm{OH}$ lase. This close relationship is the reason to believe that PTH and calcium can function both directly and indirectly as a cancer promoter. PTH can increase insulin-like growth factor 1 (IGF-I) synthesis in liver and bone, thereby increasing the pool of circulating IGF-I. PTH may act as a direct cancer promoter as a co-mitogen and anti-apoptotic factor in preneoplastic lesions expressing the PTH receptor (16). Increased intakes of calcium or dairy products have already been associated with decreased risk for colon or breast cancer in several prospective studies (6).

The independent action, namely the autocrine effect of vitamin D means the conversion of vitamin D prohormone $25(\mathrm{OH}) \mathrm{D}$, into the $1,25(\mathrm{OH}) 2 \mathrm{D}$ in the target tissue. Identification of extra-renal 1aOHlase has changed our understanding of the precise role of $25(\mathrm{OH}) \mathrm{D}$ in tissues including the prostate. Experimentally, it was shown that in peripheral macrophages cultured in serum-free media, synthesis of $1,25(\mathrm{OH}) 2 \mathrm{D}$ was not influenced by PTH even at supraphysiological concentrations, but was inhibited by its own reaction product, 1,25(OH)2D at physiological concentrations (17).

Several 1,25(OH)2D target tissues, including intestinal epithelial cells and the cardiovascular system, also have been identified as sites of nongenomic aldosterone regulation(18). Our results were short in suggesting a possible role of aldosterone in PCa pathogenesis, but encourage a future study with a larger number of patients.

The apparent limitation of the study was the small number of patients. However, these patients were enrolled in a long period 
$171-174$

of time, as we excluded any patients with a disease that required medical interventions, in order to separate the measured parameters to be independent.

Our findings indicate that, like age, race, PSA is associated with PTH as presented by very rare previous studies. Prostate cells express calcium-dependent channels that regulate cell proliferation via the control of calcium entry into the cells (19). The mechanism is not unique to prostate but common all through the body making PTH a general mitogen. Although a major culprit, PTH seems to be neglected in studies of cancer. Our study demonstrated the close relation of PTH with one of the most famous cancer markers, namely PSA. Our results do not include an explanation of the finding, but hopefully will inspire future studies on PTH and cancer in general.

\section{References}

1. Schwartz GG, Hulka BS. Is vitamin D deficiency a risk factor for prostate cancer? (hypothesis). Anticancer Res 1990; 10: 1307-1311.

2. Chen TC, Holick MF. Vitamin D and prostate cancer prevention and treatment. Trends Endocrinol Metab 2003; 14: 423-430.

3. Barreto AM, Schwartz GG, Woodruff R, Cramer SD. 25-Hydroxyvitamin D3, the prohormone of 1,25-dihydroxyvitamin D3, inhibits the proliferation of primary prostatic epithelial cells. Cancer Epidemiol Biomarkers Prev 2000; 9: 265-270.

4. Miller GJ, Stapleton GE, Ferrara JA, et al. The human prostatic carcinoma cell line LNCaP expresses biologically active, specific receptors for 1 alpha,25-dihydroxyvitamin D3. Cancer Res 1992; 52: $515-520$.

5. Nagpal S, Na S, Rathnachalam R. Noncalcemic actions of vitamin D receptor ligands. Endocr Rev 2005; 26: 662-687.

6. Garland C, Shekelle RB, Barrett-Connor E, Criqui MH, Rossof AH, Paul O. Dietary vitamin D and calcium and risk of colorectal cancer: a 19-year prospective study in men. Lancet 1985; 5: 307-309.

7. Lips P. Vitamin D physiology. Prog Biophys Mol Biol 2006; 9: 24-28.
8. Li YC, Kong J, Wei M, Chen ZF, Liu SQ, Cao LP. 1,25-Dihydroxyvitamin D3 is a negative endocrine regulator of the renin-angiotensin system. J Clin Invest 2002; 110: 229-238.

9. Schwartz GG. Vitamin D and the Epidemiology of Prostate Cancer. Semin Dial 2005; 18: 276-289.

10. Fraser DR. Exploration of possible mechanisms linking vitamin D status and dietary calcium to prostate cancer. Br J Nutr 2007; 97: 596-597.

11. Ritchie CK, Thomas KG, Andres LR, Tindall DJ, Fitzpatrick LA. Effects of the calciotrophic peptides calcitonin and parathyroid hormone on prostate cancer growth and chemotaxis. Prostate 1997; 30: 183-187.

12. Lia J, Schnieder A, Datta NS, McKauley LK. Extracellular calcium as a candidate mediator of prostate cancer skeletal metastasis. Cancer Res 2006; 77: 9065-9073.

13. Gomes RR Jr, Buttke P, Paul EM, Sikes RA. Osteosclerotic prostate cancer metastasis to murine bone are enhanced with increased bone formation. Clin Exp Metastasis 2009; 26 (7): 641-651.

14. Skinner HG, Schwartz GG. The Relation of Serum Parathyroid Hormone and Serum Calcium to Serum Levels of Prostate-Specific Antigen: A Population-Based Study. Cancer Epidemiol Biomarkers Prev 2009; 18 (11): 2869-2873.

15. Kim WT, Choi YD, Park $C$ et al. Parathyroid hormone is not involved in prostate growth in patients with benign prostatic hyperplasia. Prostate 2011; 71 (11): 1210-1215.

16. McCarty MF. Medical Parathyroid hormone may be a cancer promoter $Ð$ an explanation for the decrease in cancer risk associated with ultraviolet light, calcium, and vitamin D. Medical Hypotheses 2000; 54: 475-482.

17. Dusso AS, Finch J, Brown A et al. Extrarenal production of calcitriol in normal and uremic humans. J Clin Endocrinol Metab 1991; 72: 157-164

18. Losel RM, Feuring M, Falkenstein E, Wehling M. Nongenomic effects of aldosterone: cellular aspects and clinical implications. Steroids 2002; 67: 493-498.

19. Lallet-Daher H, Roudbaraki M, Bavencoffee A et al. Intermediateconductance $\mathrm{Ca}^{2+}$-activated $\mathrm{K}^{+}$channels (IKcal) regulate human prostate cancer cell proliferation through a close control of calcium entry. Oncogene 2009; 28: 1792-1806. 